\title{
Carbon emission trading system of China: a linked market vs. separated markets
}

\author{
Yu LIU $(\bowtie){ }^{1}$, Shenghao FENG ${ }^{2}$, Songfeng $\mathrm{CAI}^{3}$, Yaxiong ZHANG ${ }^{3}$, Xiang $\mathrm{ZHOU}^{4}$, Yanbin $\mathrm{CHEN}^{5}$, \\ Zhanming CHEN (凶) $)^{5}$ \\ 1 Institute of Policy and Management, Chinese Academy of Sciences, Beijing 100190, China \\ 2 Crawford School of Public Policy, Australian National University, Canberra ACT 0200, Australia \\ 3 National Development and Research Commission, State Information Centre, Beijing 100045, China \\ 4 Sun Yet-Sen Business School, Sun Yet-Sen University, Guangzhou 510275, China \\ 5 School of Economics, Renmin University of China, Beijing 100872, China
}

(C) Higher Education Press and Springer-Verlag Berlin Heidelberg 2013

\begin{abstract}
The Chinese government intends to upgrade its current provincial carbon emission trading pilots to a nationwide scheme by 2015 . This study investigates two of scenarios: separated provincial markets and a linked interprovincial market. The carbon abatement effects of separated and linked markets are compared using two pilot provinces of Hubei and Guangdong based on a computable general equilibrium model termed SinoTERMCo2. Simulation results show that the linked market can improve social welfare and reduce carbon emission intensity for the nation as well as for the Hubei-Guangdong bloc compared to the separated market. However, the combined system also distributes welfare more unevenly and thus increases social inequity. On the policy ground, the current results suggest that a well-constructed, nationwide carbon market complemented with adequate welfare transfer policies can be employed to replace the current top-down abatement target disaggregation practice.
\end{abstract}

Keywords linked market, carbon emission trade, SinoTERMCo2

\section{Introduction}

Reducing greenhouse gas emissions is an important measure in addressing climate change (Yi et al., 2007; Ren, 2008). China has attached importance to energy savings and emission reduction. The Twelfth Five Year Plan of China sets an agenda to use carbon emission

Received February 1, 2013; accepted March 27, 2013

E-mail: liuyu@mx.cei.gov.cn (Yu LIU), chenzhanming@ruc.edu.cn, chenzhanming@pku.edu.cn (Zhanming CHEN) markets to control carbon dioxide emissions. At the beginning of 2012, the national government hand-picked seven provinces and five cities as first-stage carbon emission trading pilots (IOSCPRC, 2011). These pilots are responsible for initiating intra-regional trading markets by the end of 2013 and up-scaling the regional markets towards a nationwide market from 2015 onwards (Su et al., 2012). This study investigates the impact of linking two such pilots, namely Hubei and Guangdong, in order to gain insights on the benefits and obstacles of combining domestic carbon markets in China. The most significant benefit of linking carbon markets is derived from higher economic efficiency as this scheme allows abatement to be carried out in lower cost regions and thus enhances trading parties' welfare (Nordhaus and Boyer, 1999).

The most significant potential obstacle of linking markets concerns equity. The combined carbon markets may distribute welfare gain unevenly across different regions and players within regions. The uneven distribution is straightforward in partial equilibrium analysis. In a partial equilibrium analysis all parties would be better off from emissions trading but regions with steeper marginal abatement cost curves will gain more than the other regions (Flachsland et al., 2009; Chen et al., 2013). This is going to cause trouble when regions are looking for comparable gains from the combination. Moreover, since more developed regions generally have steeper marginal abatement curves (Stern et al., 2011), linking carbon markets might widen regional income inequality. Adopting general equilibrium analysis, however, reveals more complicated and in-depth welfare distribution mechanisms (Wei et al., 2009; He and Li, 2010; Li et al., 2010; Chen and Chen, 2011a, b, 2013a, b). First, general equilibrium analysis could model an economy in richer detail. A computable 
general equilibrium (CGE) model can distinguish between labor and capital, commodities and industries, exports and imports, consumers and investors and so forth (Chen et al., 2012; Yang and Chen, 2011). Polices that benefit a province at the macro level do not necessarily benefit all the players within it. For example, an industry whose production technology is labor-intensive might expand at the expense of another industry whose production technology is capital-intensive. Hence, when trading makes a province to better off, some of the entities within the province may be worse off.

Second, general equilibrium effects, in particular tax interaction effects and terms of trade effects, may significantly influence welfare distribution (Babiker et al., 2004). The tax interaction effects transfer welfare from permit-selling regions to permit-buying regions. When carbon markets are linked, permit-selling regions will experience higher carbon prices. In the presence of preexisting tax distortions, higher carbon prices generate negative tax interaction effects and exacerbate the preexisting tax distortion (Lipsey and Lancaster, 1956). After linking, permit-buying regions will experience lower carbon prices and reduce negative tax interaction effects, thus ameliorating the pre-existing distortion. Previous numerical CGE studies have shown that when the preexisting tax distortion is large, it could dominate the direction of welfare changes (Babiker et al., 2004; Webster et al., 2010).

The terms of trade effects, on the other hand, are likely to 'transfer' welfare from permit-buying regions to permitselling regions. After linking, permit-selling regions will face higher carbon costs and permit-buying regions will face lower carbon costs. Hence, permit-selling regions are more likely to experience improvements in terms of trade whereas permit-buying regions are more likely to experience deteriorations in terms of trade. However, the direction of welfare transfer represented by the terms of trade effect may not be ambiguous. Babiker et al. (2004) proposes that it is possible for permit-selling regions to experience a negative terms of trade effect due to the loss of cost competitiveness they enjoy in autarky, although numerical simulation has not been able to confirm this hypothesis. Li and Huang (2005) use a CGE model to assess the potential 'transfer' impact of the international emissions trading market. Moreover, as Webster et al. (2010) explains, the magnitude of the terms of trade effect also hinges on factors such as the share of trade in a region's GDP and the substitutability between domestic and imported goods as well as how far the autarky carbon prices are from the uniform carbon price in an integrated carbon market. Nevertheless, Webster et al. (2010) demonstrates the impact of terms of trade effect can be large as supported by a strong correlation between terms of trade gain and welfare gain in a numerical simulation.

There are also several studies focusing on carbon emission evaluation based on other perspectives. Liang and Wei (2012) use a CGE model to analyze the impact of the carbon tax. Zhang et al. (2011) and Hubacek et al. (2012) use LEAP model and IPAT framework, respectively, to evaluate the effect of different scenarios of carbon emissions. Lin et al. (2011) use the DEA method to measure the environmental and energy performance during the economic development process in 30 provinces.

The above analysis shows that the magnitude and direction of welfare distribution to different regions upon linking carbon markets can be uncertain. While the taxinteraction effects and terms of trade effects both bear significant impacts but potentially act in opposite directions, it is possible for some permit-selling regions and some permit-buying regions to be worse off ${ }^{1}$. This has been shown in previous numerical simulations (Babiker et al., 2004; Lokhov and Welsch, 2008; Webster et al., 2010). Hence, if some entities are set to be worse off upon joining an integrated carbon market, it will impede the linking of existing pilot markets.

This study attempts to quantitatively explore the impact of connecting regional pilot carbon markets in the context of Hubei and Guangdong. The analysis provides policy makers insight on how different regions and entities are likely to be affected as well as identifying the underlying factors for these impacts. We employ a bottom-up, multiregional, static CGE model of China to do the analysis. The rest of this paper is organized as follows: section 2 explains the model and the simulation design; section 3 sets out an overview of Hubei and Guangdong; section 4 interprets the simulation results; and section 5 draws policy implications.

\section{Model and simulation}

\subsection{A multi-regional CGE model for China $\left(\right.$ SinoTERMCo2 $\left.{ }^{2)}\right)$}

We employ a bottom-up, multi-regional, static CGE model, namely SinoTERMCo2. SinoTERMCo2 is a special version of SinoTERM (Horridge and Wittwer, 2008), which in turn adapts from the generic TERM model (Horridge et al., 2005). A typical top-down model such as CHINAGEM (Mai et al., 2012) allocates national outputs to each region according to their respective regional output shares, while goods that belong to the same commodity category all have the same basic prices, regardless of their origin. This allows a national shock to have an impact on a particular region, but it does not allow the simulation of a regional shock that only impacts the price of the goods within that region. Being a bottom-up model however,

1) However, it is impossible for all regions to be worse off since the overall welfare change must remain positive.

2) "TERM" refers to "The Enormous Regional Model". 
TERM treats each region of the country as if it is an individual "economy". Under this setup, goods that belong to the same commodity category but are produced in different regions can have different prices. Thus by using a TERM-inspired model we could observe issues about differential prices in electricity and other traded goods across provinces.

We upgraded SinoTERM to SinoTERMCo2 in two aspects. First, we updated the database. The SinoTERM database is based on the 2002 input-output tables. We updated SinoTERMCo 2 by using the 2007 China inputoutput tables for 31 provinces. This update makes SinoTERMCo2 a much closer representation of China's economic structure than its predecessor. Second, we added a carbon dioxide emissions trading and accounting module. Our carbon emissions trading module is adapted from the method used in McDougall and Golub's (2007) revised version of the GTAP_E model (Burniaux and Truong, 2002).

We created the provincial level carbon dioxide emissions account by putting data from various sources into the following formula:

$$
E_{i}=Q_{i} \times A_{i} \times B_{i},
$$

where $E_{i}$ is the amount of carbon emissions generated by energy product $i ; Q_{i}$ is the total consumption of energy product $i ; A_{i}$ is an emitting factor based on energy content and $B_{i}$ is a factor that converts from standard quantity units to energy units. We obtained the data for $E_{i}$ from the 2007 China input output table for 30 provinces and 42 industries. We obtained data for $A_{i}$ from the IPCC emitting factors for different energy products; and data for $B_{i}$ from the China Energy Statistical Year Book. Appendix 1 summarized the data for $A_{i}$ and $B_{i}$.

\subsection{Deriving absolute emissions reduction targets}

The level of emissions reduction designed for each carbon market is critical since it determines the level of stringency of each scheme. In the absence of official emission caps we assume each provincial carbon market adapts a target that is comparable to its provincial intensity-based emissions reduction target. We convert these intensity-based targets to absolute targets through Eqs. (2) - (6):

$$
\begin{gathered}
E T_{15}=100 \times\left(E B_{15}-E P_{15}\right) / E B_{15}, \\
E B_{15}=E_{10} \times(1+E G)^{5}, \\
E P_{15}=Y B_{15} \times E I_{10} \times\left(1-E I T_{15}\right), \\
Y B_{15}=Y_{10} \times(1+Y G)^{5},
\end{gathered}
$$

$$
E I_{10}=E_{10} / Y_{10} .
$$

The meanings of the variables are shown in Table 1.

Table 1 Meanings for variables in equations

\begin{tabular}{lc}
\hline Variable & Meaning \\
\hline$E T_{15}$ & Absolute emissions reduction target, 2011-2015 (\%) \\
$E B_{15}$ & BAU emissions in 2015 \\
$E P_{15}$ & Policy emissions in 2015 \\
$E_{10}$ & Emissions in 2010 \\
$E G$ & Annual emissions growth rate, 2011-2015 \\
$Y B_{15}$ & BAU GDP in 2015 \\
$E I_{10}$ & Emissions intensity of GDP in 2010 \\
$E I T_{15}$ & GDP in 2010 \\
$Y_{10}$ & Antensity-based emissions reduction target, 2011-2015 \\
$Y G$ & Annual GDP growth rate, 2011-2015 \\
\hline
\end{tabular}

By substituting and rearranging Eqs. (2) - (6), we obtain Eq. $(7)^{1)}$ :

$$
\begin{aligned}
E T_{15}= & {\left[(1+E G)^{5}-(1+Y G)^{5}\right.} \\
& \left.\times\left(1-E I T_{15}\right)\right] /(1+E G)^{5} .
\end{aligned}
$$

Equation (7) indicates that the absolute emissions reduction target $\left(E T_{15}\right)$ can be converted from three factors. First, $E T_{15}$ is negatively related with GDP growth rate $(Y G)$. According to the $12^{\text {th }}$ FYP for Guangdong and the $12^{\text {th }}$ FYP for Hubei the expected annual GDP growth rate $(Y G)$, between 2011 and 2015, are $8 \%$ and $10 \%$, respectively. Second, $E T_{15}$ is positively related with the intensity-based emissions reduction targets $\left(E I T_{15}\right)$ for the two provinces. According to the State Council's " $12^{\text {th }}$ FYP - Controlling Green House Gas Emissions Plan", the targeted emissions intensity reduction for Hubei and Guangdong is $17 \%$ and $19.5 \%$, respectively.

Third, $E T_{15}$ is positively related to the rate of emissions growth $(E G)$. In this case we do not have official targets or expectations for $E G$ on the provincial level. However, we know that the elasticity of energy consumption $(E E C)$ with respect to GDP in 2010 is 0.80 and 0.79 for Hubei and Guangdong, respectively. And we also know the GDP growth rates in $2010\left(Y G_{10}\right)$ are $10 \%$ and $8 \%$ for Hubei and Guangdong, respectively. From these numbers we infer that the growth rates of energy consumption in 2010 are $7.97 \%$ and $6.35 \%$ for Hubei and Guangdong, respectively. Then we assume that growth rates of emissions between 2011 and 2015 are the same as the growth rate of energy consumption in 2010. In other words, we assume that $E G$ is $7.97 \%$ and $6.35 \%$ for Hubei and Guangdong, respectively. Hence, with the three variables on the right hand side of Eq. (7) given, we derive the left hand side of

1) We assume that the GDP variance before and after mitigation is negligible. 
Eq. (7), $E T_{15}$, to be $8.09 \%$ and $13.07 \%$ for Hubei and Guangdong, respectively. Table 2 summarizes the values we used for the derivation of $E T_{15}$.

Table 2 indicates that, based on the historical GDP growth rate, the elasticity of energy consumption and the $12^{\text {th }}$ FYP emissions intensity targets, if others being equal, Guangdong's absolute emissions reduction target $(13.07 \%)$ is more stringent than Hubei's (8.09\%).

\subsection{Simulation scenarios}

We devise two simulation scenarios, namely NoLink and Link. Scenario NoLink simulates the impact of using a province-wide carbon market (as the single tool) to achieve the assigned provincial emissions reduction targets for Hubei and Guangdong, respectively. Under this scenario, emission permits are not allowed to be traded between the two provinces. Each province thus internally discovers the implied price of a unit of carbon emissions within that province. Due to the various differences between the two provinces, the two carbon markets will issue different units of permits, result in different levels of abatements, and discover different carbon prices.

Scenario Link simulates the impact of using an integrated carbon market between Hubei and Guangdong (also as the single tool) to achieve the assigned emissions reduction targets for the two provinces combined. Under this scenario, emission permits are allowed to be traded between the two provinces, i.e., the link is bilateral and direct. Hence the permit prices will converge to a single price between the two regions, although it is still possible for the two provinces to issue different units of permits and result in different levels of abatements.

\section{An overview of Hubei and Guangdong}

The choice for studying a link between Hubei and Guangdong's carbon markets is arbitrary. In reality the integration would be more than just these two provinces. We could have simulated the integration of all the 7 pilot carbon markets, or simulated the integration of all the 31 provinces in the country. However, for simplicity, we decided to just combine two. The results will preserve the essence of a larger-scope integration. That being said, studying the connection between Hubei and Guangdong is a reasonable choice since these two provinces are different in some key aspects.

First, Hubei and Guangdong are at different stages of development. Table 3 presents an overview of the two provinces. On one hand, sitting in the geographical centre of China, Hubei's GDP is less than a third of Guangdong's, whereas its population is more than half of Guangdong's. The Economist (2011) compares Hubei's GDP per capita as that of Angola's in 2010. On the other hand, being adjacent to Hong Kong, Guangdong boosts the largest population and the highest GDP in China. The same survey (Economist, 2011) presents Guangdong's GDP per capita as that of Kazakhstan's, in $2010^{1)}$.

The sectorial composition of the two provinces also reveals differences in the stage of development. As it is shown in Table 4, despite having a similar-sized primary industry, Guangdong's secondary industry is more than six times larger than Hubei's, while the former's service industry is also more than three times the size of the latter's.

Second, Hubei and Guangdong also have different expenditure patterns. Table 5 shows that consumption as a share of GDP is larger in Guangdong than in Hubei. Regional trade significantly contributes to regional GDP in both provinces-both Hubei and Guangdong are net regional importers. However, international trade contributes much more significantly to GDP in Guangdong than in Hubei.

Third, the emission patterns of the two provinces are also different. Tables 6 and 7 show the 2007 carbon dioxide emissions by fuel and by industry in Hubei and Guangdong, respectively. In terms of emissions from fuel,

Table 2 Values for Eq. (7)

\begin{tabular}{lcccccc}
\hline Province & $Y G$ & $E I T_{15}$ & $E E C$ & $Y G_{10}$ & $E G$ & $E T_{15}$ \\
\hline Hubei & $10 \%$ & $17 \%$ & 0.80 & $10 \%$ & $7.97 \%$ & $8.09 \%$ \\
Guangdong & $8 \%$ & $19.5 \%$ & 0.79 & $8 \%$ & $6.35 \%$ & $13.07 \%$ \\
\hline
\end{tabular}

Table 3 An overview of Hubei and Guangdong, 2010

\begin{tabular}{|c|c|c|c|c|c|c|}
\hline \multirow{2}{*}{ Province } & \multicolumn{2}{|c|}{ GDP } & \multicolumn{2}{|c|}{ Population } & \multicolumn{2}{|c|}{ GDP per capita } \\
\hline & $100 \times 10^{9} \mathrm{CNY}$ & Closest to & 10,000 & Closest to & $\mathrm{CNY}$ & Closest to \\
\hline Hubei & 15,967 & Nigeria & 5,728 & Italy & 27,906 & Angola \\
\hline Guangdong & 45,473 & Indonesia & 10,441 & Philippine & 44,736 & Kazakhstan \\
\hline
\end{tabular}

Sources: China data online (2012) for data; The Economist (2011) for country comparison.

1) After adjusting for purchasing power. 
Table 4 Sector composition $\left(\times 10^{9} \mathrm{CNY}\right), 2007$

\begin{tabular}{lccc}
\hline Province & Primary & Secondary & Tertiary \\
\hline Hubei & 230 & 908 & 450 \\
Guangdong & 271 & 5,714 & 1,570 \\
\hline
\end{tabular}

Source: SinoTERMCo2 database. both provinces rely predominately on coal, with coal contributing $70 \%$ and $65 \%$ of total carbon emissions in Hubei and Guangdong, respectively. The main difference is the reliance on gas: gas contributed to less than $0.7 \%$ of emissions in Hubei, whereas it contributed to more than $8 \%$ of emissions in Guangdong.

Table 5 GDP expenditure $\left(\times 10^{9} \mathrm{CNY}\right), 2007$

\begin{tabular}{lcccrrrrrr}
\hline Province & C & I & G & RExp & RImp & Exp & Imp & NMar & Stock \\
\hline Hubei & 375 & 369 & 135 & 634 & -900 & 66 & -55 & 12 & 14 \\
Guangdong & 1,281 & 839 & 312 & 2,309 & $-3,249$ & 2,910 & $-1,580$ & -301 & 37 \\
\hline
\end{tabular}

Notes: $\mathrm{C}$ denotes private consumption, I denotes investment, $\mathrm{G}$ denotes government consumption, RExp denotes export to other provinces, RImp denotes import from other provinces, Exp denotes export abroad, RImp denotes import from abroad, and NMar denotes net margin.

Source: SinoTERMCo2 database.

Table 6 Carbon dioxide emissions (10,000 tonne), Hubei 2007

\begin{tabular}{|c|c|c|c|c|}
\hline Hubei & Coal & Petroleum & Gas & Total \\
\hline MetalSmelt & $4,384.6$ & 679.5 & 12.9 & $5,076.9$ \\
\hline ElecSteam & $4,635.8$ & 14.7 & 4.8 & $4,655.3$ \\
\hline NonMetalMine & $3,961.5$ & 302.2 & 18.5 & $4,282.2$ \\
\hline Chemical & $2,712.2$ & 931.9 & 27.2 & $3,671.3$ \\
\hline TransWarehse & 38.8 & $2,434.7$ & 0 & $2,473.5$ \\
\hline Contruction & 279.3 & 348.9 & 0 & 628.3 \\
\hline Agriculture & 116 & 387.1 & 5.4 & 508.5 \\
\hline HotelsDining & 255.4 & 172.8 & 12.7 & 440.9 \\
\hline FoodTabaco & 189.5 & 239 & 2.2 & 430.7 \\
\hline GenerlSpelEqp & 152.4 & 193.8 & 41.1 & 387.3 \\
\hline Other industries & 800.8 & $1,502.6$ & 44.5 & $2,347.8$ \\
\hline Private consume & 985 & 118.1 & 529.7 & $1,632.8$ \\
\hline Total & $17,526.3$ & $7,207.2$ & 169.2 & $24,902.6$ \\
\hline
\end{tabular}

Source: SinoTERMCo2 database.

Table 7 Carbon dioxide emissions (10,000 tonne), Guangdong 2007

\begin{tabular}{lcccc}
\hline Guangdong & Coal & Petroleum & Gas & Total \\
\hline ElecSteam & $11,514.8$ & $1,205.2$ & 150.7 & $12,870.8$ \\
NonMetalMine & $2,711.5$ & 412.8 & 462.4 & $3,586.7$ \\
Chemical & 530.7 & $1,290.5$ & 662.7 & $2,483.9$ \\
MetalSmelt & 1,540 & 354 & 213.5 & $2,107.5$ \\
TransWarehse & 0.9 & 1,988 & 0.3 & $1,989.2$ \\
Contruction & $1,091.1$ & 92.1 & 43.6 & $1,226.9$ \\
Textile & 514 & 72.4 & 25.3 & 611.8 \\
HotelsDining & 375.8 & 54.3 & 19.8 & 449.9 \\
CrudeOilGas & 73.4 & 340.3 & 0.6 & 414.3 \\
GenerlSpelEqp & 52.7 & 201.1 & 134.1 & 387.9 \\
Other industries & 374.7 & 1,558 & 673.4 & $2,606.1$ \\
Private consume & 567.1 & 896.7 & 863.3 & 2,327 \\
Total & $18,779.7$ & $7,568.6$ & $2,386.5$ & $28,734.9$ \\
\hline
\end{tabular}

Source: SinoTERMCo2 database. 
Table 8 Top ten emission intensive industries, 2007

\begin{tabular}{|c|c|c|c|}
\hline \multicolumn{2}{|l|}{ Hubei } & \multicolumn{2}{|l|}{ Guangdong } \\
\hline Industry & tonne $/ 10,000 \mathrm{CNY}$ & Industry & tonne/10,000 CNY \\
\hline NMetalProdt & 11.741 & NonMetalMine & 4.751 \\
\hline ElecSteam & 10.469 & ElecSteam & 4.656 \\
\hline MetalSmelt & 7.665 & NMetalProdt & 2.652 \\
\hline Chemical & 4.227 & MetalSmelt & 0.981 \\
\hline TransWarehse & 3.211 & CrudeOilGas & 0.952 \\
\hline CrudeOilGas & 1.868 & TransWarehse & 0.911 \\
\hline MetalMine & 1.773 & PaprPrntCult & 0.51 \\
\hline NonMetalMine & 1.704 & Chemical & 0.427 \\
\hline HotelsDining & 1.466 & Post & 0.427 \\
\hline PetrlRefCoke & 1.123 & Textiles & 0.329 \\
\hline
\end{tabular}

Source: SinoTERMCo2 database.

Fourth, in general, Hubei is more emissions intensive than Guangdong. Hubei's emissions intensity of GDP (0.41 tonne per $1,000 \mathrm{CNY}$ ) is much higher than of Guangdong ( 0.12 tonne per 1,000 CNY). Hubei's emission per capita (4.66 tonne per capita) is also higher than Guangdong's (3.29 tonne per capita). Table 8 shows the same pattern on the industry level: the 10 most carbon intensive industries are 'dirtier' in Hubei than in Guangdong (Appendix 2 shows emissions intensity of all industries).

However, there are nevertheless some similarities between the two provinces. First, despite Guangdong's private consumption being almost three times as large as that of Hubei, their emissions from private consumption do not differ by a large margin. Second, both provinces' emissions are highly concentrated in a few emissionintensive industries. The top five carbon emitting industries contribute $76 \%$ and $74 \%$ to the total emissions in Hubei and Guangdong, respectively. Therefore, it is expected that the introduction of a carbon price would impact particularly these emission-intensive industries.

\section{Simulation analysis}

4.1 Macro level provincial impacts on Hubei and Guangdong

Under both Scenario NoLink and Scenario Link, carbon markets increase the cost of carbon emitting activities - be it for industrial production or household consumption. This brings about a general increase in the price level and a general fall in real GDP. The fall in real GDP is accompanied by a general decline of economic activities on both the demand and supply side of the economy. These declines are shown in Table 9. On the demand side, the higher cost of production deters investment. The general increase in output price reduces the price-competitiveness of Hubei's and Guangdong's output thus hindering their export. The weakening demand in the two provinces also constrains their import. Household consumption falls as income decreases. Although it does not fall as much as GDP does since the permit selling income is assumed to be recycled back to consumers ${ }^{1)}$. A notable exception is that Hubei's consumption increases after linking, a point we will address in the following subsection (Section 4.2). On the supply side, the dampened investment reduces capital. Labor also moves out of these provinces due to the decline of real wage offered.

Under the NoLink Scenario, the decline of economic activities is uniformly larger in Guangdong than is the decline in Hubei (Table 9). This implies that under the current provincial emission intensity targets, Hubei's abatement target is less stringent than Guangdong's. As it is shown in Table 10, the permit price in Guangdong is 7 times higher than in Hubei.

The simulation results suggest linking improves efficiency for the two provinces when they are considered as a single bloc. The last column of Table 10 shows combination increases real GDP and real consumption and reduces average abatement cost for the bloc. This confirms the result that prevails in both partial equilibrium and general equilibrium analysis, that connecting carbon markets unambiguously improves overall efficiency.

However, the linkage has different implications to each individual province. Upon the linking, each province now has two abatement options. They can choose a combination of "self-abatement" and "purchased-abatement",

1) Giving all revenues back to consumers might not be the most realistic assumption, since in reality the revenues can be used for various purposes, e.g. compensating emissions-intensive, export-oriented/import-competing industries, reducing other pre-existing taxes, restoring budget deficit, or investing in R\&D. 
Table 9 Provincial macro variables (\% change)

\begin{tabular}{lrrrr}
\hline & \multicolumn{2}{c}{ NoLink } & & \multicolumn{2}{c}{ Link } \\
\cline { 2 - 4 } & Hubei & Guangdong & Hubei & Guangdong \\
\hline C & -0.16 & -0.32 & 0.02 & -0.19 \\
I & -1.96 & -3.42 & -4.29 & 0.00 \\
G & 0.00 & 0.00 & 0.00 & -0.23 \\
X & -0.47 & -0.73 & -1.39 & -0.32 \\
M & -0.95 & -0.71 & -2.02 & -0.76 \\
GDP & -1.13 & -2.13 & -2.57 & -0.48 \\
Lab & -0.46 & -1.39 & -1.15 & -1.01 \\
Cap & -1.80 & -2.75 & -3.92 & -0.66 \\
Real wage & -0.75 & -1.68 & -1.32 & 0.27 \\
Pgdp & 0.28 & 0.82 & 0.91 & 0.11 \\
CPI & -0.01 & 0.36 & 0.17 & 0.06 \\
Pexp & 0.12 & 0.18 & 0.35 & 0.00 \\
Pimp & 0.00 & 0.00 & 0.00 & \\
\hline
\end{tabular}

Source: SinoTERMCo2 simulation results.

Table 10 Welfare change and abatement cost

\begin{tabular}{|c|c|c|c|c|c|c|c|c|c|c|}
\hline \multirow[t]{2}{*}{ Scenario } & \multirow[t]{2}{*}{ Unit } & \multicolumn{3}{|c|}{ NoLink } & \multicolumn{3}{|c|}{ Link } & \multicolumn{3}{|c|}{ Link-NoLink } \\
\hline & & Hubei & Guangdong & BLOC & Hubei & Guangdong & BLOC & Hubei & Guangdong & BLOC \\
\hline $\begin{array}{l}\text { Real GDP } \\
\text { change }\end{array}$ & $10 \mathrm{~m} . \mathrm{y}$ & -734 & $-5,446$ & $-6,180$ & $-1,666$ & $-1,943$ & $-3,608$ & -931 & 3,504 & 2,572 \\
\hline $\begin{array}{l}\text { Consumption } \\
\text { change }\end{array}$ & $10 \mathrm{~m} . \mathrm{y}$ & -58 & -415 & -474 & 9 & -240 & -231 & 67 & 176 & 243 \\
\hline $\begin{array}{l}\text { Permit-selling } \\
\text { revenue }\end{array}$ & $10 \mathrm{~m} . \mathrm{y}$ & 372 & 2,791 & 3,163 & 784 & 1,050 & 1,834 & 412 & $-1,741$ & $-1,329$ \\
\hline Abatement & $10 \mathrm{~m} . \mathrm{t}$ & 2.4 & 4.1 & 6.4 & 2.4 & 4.1 & 6.4 & 0.0 & 0.0 & 0.0 \\
\hline Self-abatement & $10 \mathrm{~m} . \mathrm{t}$ & 2.4 & 4.1 & 6.4 & 4.7 & 1.8 & 6.4 & 2.3 & -2.3 & 0.0 \\
\hline $\begin{array}{l}\text { Purchased- } \\
\text { abatement }\end{array}$ & $10 \mathrm{~m} . \mathrm{t}$ & 0.0 & 0.0 & 0.0 & -2.3 & 2.3 & n.a. & -2.3 & 2.3 & n.a. \\
\hline Permit price & $y / t$ & 15.4 & 103.4 & n.a. & 35.9 & 35.9 & n.a. & 20.5 & -67.6 & n.a. \\
\hline $\begin{array}{l}\text { Permit trade } \\
\text { income }\end{array}$ & $10 \mathrm{~m} . \mathrm{y}$ & 0.0 & 0.0 & 0.0 & 82.2 & -82.5 & n.a. & 82.2 & -82.5 & n.a. \\
\hline $\begin{array}{l}\text { Average abate- } \\
\text { ment cost }\end{array}$ & $y / t$ & 310 & 1,341 & 961 & 703 & 478 & 562 & 393 & -863 & -399 \\
\hline
\end{tabular}

Note: million (m); CNY (y); tonne (t), BLOC: sum of HB and GD.

Source: SinoTERMCo2 simulation results.

which means to pay the other province for the abatement activities to be carried out by the seller of the emission permits. Therefore the linkage will reallocate emitting activities between the two provinces. As the pre-linking permit price differential gives it a competitive edge in "producing" abatement, Hubei will become the net permit seller once the two carbon markets integrate. We see in Table 10 that under Scenario Link, Guangdong's emissions reduction target will be achieved by $44 \%$ of self-abatement and $56 \%$ of purchased abatement. On the other hand, also under Scenario Link, Hubei's emissions reduction target will be achieved by $196 \%$ of self-abatement and $-96 \%$ of purchased abatement. Hence after linking there will be a reallocation of emitting activities from Guangdong to Hubei.

Not only the emitting activities will be reallocated, but the prices of the emitting permits will also converge to a new level under a single carbon market. This new price will sit between the two single market prices (see Table 10). Under Scenario Link, Guangdong will face a carbon price that is $67.5 \mathrm{CNY}$ per tonne lower than under Scenario No-link; whereas Hubei will face a carbon price that is 20.5 
CNY per tonne higher than under Scenario NoLink. Hence marginal abatement cost will increase in Hubei but decrease in Guangdong.

The effects of the reallocation of emitting activities and the convergence of permit price together 'transfer' economic activities from Hubei to Guangdong. Both the reallocation of emitting activities and the convergence of permit price have positive impacts on Guangdong's economy, for the province will carry out less abatement at a lower price. In contrast, both the reallocation of emitting activities and the convergence of permit price have negative impact on Hubei's economy, for the province will commit more abatement at a higher price. As a result, the relative general decline in economic activities between Hubei and Guangdong are reversed. Table 10 shows that after combination real GDP falls by 9,310 million CNY or 163 CNY per capita in Hubei but increases by 35,040 million CNY or $371 \mathrm{CNY}$ per capita in Guangdong. Table 9 also shows Hubei registers larger declines than Guangdong in all areas except for real consumption.

The simulation results also demonstrate that the economic gain in real consumption is distributed unevenly. As compared to a no carbon market, Hubei's consumers benefited more than Guangdong's in an integrated market, since real consumption change is positive for Hubei and negative for Guangdong. However comparing with separated carbon markets, Hubei's consumer actually gain less than Guangdong's. As shown in Table 10, that after linking real consumption increases by 670 million CNY or 11.76 CNY per capita in Hubei and 1,760 million CNY or 18.63 CNY per capita in Guangdong. Hence Guangdong's consumers on average benefit more than Hubei's consumers.

The above results should concern Hubei's governors when considering combining their carbon market with Guangdong's. If Hubei's governors are concerned about Hubei resident's living standards, they might seek to ensure Hubei's per capita real consumption increases as much as it does in Guangdong. If Hubei's governors are concerned about provincial GDP or GDP per capita figures, they might oppose combining Hubei's carbon markets with Guangdong's.

\subsection{Decomposing changes in real consumption}

Perhaps the most important simulation result is the increase in consumption for both Hubei and Guangdong after combining markets. In this section we identify the driving factors for this result. First we decompose contributions to changes in real consumption. In our model Eq. (8) holds:

$$
C=\partial Y,
$$

Eq. (8) specifies that nominal consumption $(C)$ is a fixed proportion $(\partial)$ of nominal household income $(Y)$. Lineariz- ing Eq. (1) gives Eq. (9),

$$
C\left(p_{c}+x_{c}\right)=\partial Y(\alpha+y),
$$

where $p_{c}$ and $x_{c}$ are percentage changes in CPI and real consumption respectively, and $\alpha$ and $y$ are percentage changes in $\partial$ and $Y$ respectively. Since $\alpha=0$, rearranging Eq. (9) gives Eq. (10):

$$
x_{c}=y-p_{c} .
$$

Our model specifies nominal household income $(Y)$ by Eq. (11):

$$
Y=N+L+K+P M+P M T R D,
$$

where $N, L, K, P M$, and $P M T R D$ represent nominal income from land, labor, capital, permit-selling within the province, and permit-selling to other provinces. Linearizing Eq. (11) gives Eq. (12):

$$
\begin{aligned}
y= & S_{n} \times w_{n} \times S_{l} \times w_{l} \times S_{k} \times w_{k} \times S_{p m} \times w_{p m} \\
& \times S_{\text {pmtrd }} \times w_{\text {pmtrd }},
\end{aligned}
$$

where $S_{n}, S_{l}, S_{k}, S_{p m}$ and $S_{p m t r d}$ denote the share of each income source in total household income, and $w_{n}, w_{l}, w_{k}$, $w_{p m}$ and $w_{p m t r d}$ represent the percentage nominal change in each income source.

Thus substituting Eq. (12) into Eq. (10) gives Eq. (13):

$$
\begin{aligned}
x_{c}= & S_{l} \times w_{l}+S_{k} \times w_{k}+S_{n} \times w_{n}+S_{p m} \times w_{p m} \\
& +S_{\text {pmtrd }} \times w_{\text {pmtrd }}-p_{c} .
\end{aligned}
$$

Table 11 summarizes values for Eq. (13) for Hubei and Guangdong under both scenarios. The contribution from permit-selling stands out as the sole/largest positive driving factor to change in real consumption. Under Scenario NoLink, Hubei sells fewer permits at a lower price; under Scenario Link, however, it sells more permits at a higher price. This extra permit-selling income, both within Hubei and Guangdong, led to the increase in real consumption in Hubei after combining emission trading markets. In fact, thanks to recycling permit-selling income to consumers, real consumption does not fall as much as real GDP. This is an important finding since it suggests real consumption (welfare) could fall far more than the current levels if permit-selling revenues were not recycled directly to consumers.

We decompose contributions to changes in real GDP from both the income side and expenditure side. In our model we have GDP from the income side $\left(Y_{\text {inc }}\right)$ composed as Eq. (14):

$$
Y_{\text {inc }}=A+L+K+N+\text { ProdTax }+ \text { ComTax, }
$$

where $A, L, K, N$, ProdTax, and ComTax denote technology, labor, capital, land, production tax, and commodity tax, respectively. Linearizing Eq. (8) give 
Table 11 Contribution to percentage changes in real consumption

\begin{tabular}{|c|c|c|c|c|}
\hline \multirow{2}{*}{ Real Consumption } & \multicolumn{2}{|c|}{ NoLink } & \multicolumn{2}{|c|}{ Link } \\
\hline & Hubei & Guangdong & Hubei & Guangdong \\
\hline$x_{c}$ & -0.16 & -0.32 & 0.02 & -0.19 \\
\hline \multicolumn{5}{|l|}{$=$} \\
\hline$S_{l} \times w_{l}$ & -1.08 & -2.27 & -2.04 & -0.87 \\
\hline$S_{k} \times w_{k}$ & -0.18 & -0.41 & -0.38 & -0.15 \\
\hline$S_{n} \times w_{n}$ & 0.00 & 0.00 & 0.00 & 0.00 \\
\hline$S_{p m} \times w_{p m}$ & 1.13 & 2.74 & 2.37 & 1.03 \\
\hline$S_{p m t r d} \times w_{p m t r d}$ & 0.00 & 0.00 & 0.25 & -0.08 \\
\hline$-p_{c}$ & 0.01 & -0.36 & -0.17 & -0.11 \\
\hline houslack & -0.03 & -0.03 & -0.01 & -0.01 \\
\hline Sum RHS & -0.16 & -0.33 & 0.02 & -0.19 \\
\hline
\end{tabular}

Note: Houslack is a slack variable; it is used to allow regional consumption to accommodate regional consumption with national constraint. Source: SinoTERMCo2 simulation results.

Eq. (15):

$$
y_{i n c}=\sum_{i} S_{i} x_{i}
$$

where $S_{i}$ denotes the weight of component $i$ in GDP and $x_{i}$ denotes the percentage change of component $I$ in real terms.

The GDP from the expenditure side $\left(Y_{\exp }\right)$ function is written as Eq. (16) in our model:

$$
\begin{aligned}
Y_{\exp }= & C+I+G+E_{r}-M_{r}+E-M \\
& + \text { NetMar }+Q
\end{aligned}
$$

where $C, I, G, X_{\mathrm{r}}, M_{r}, X, M$, NetMar, and $Q$ denote consumption, investment, government spending, regional export, regional import, international export, international import, net margin, and stock, respectively. Linearizing Eq. (16) gives Eq. (17):

$$
y_{\exp }=\sum_{j} S_{j} x_{j}
$$

where $S_{j}$ denotes the weight of component $i$ in GDP and $x_{j}$ denotes the percentage change of component $i$ in real terms.

Combining Eq. (15) and Eq. (17) and moving the real consumption term $S_{c} x_{c}$ to the left-hand-side we obtain Eq. (18):

$$
S_{c} x_{c}=\sum_{i} S_{i} x_{i}-\sum_{u} S_{u} x_{u},
$$

where $u$ denotes components on the GDP expenditure side other than consumption.

In Table 12, the sum of $S_{\text {tprod }} x_{\text {tprod }}$ and $S_{\text {tcom }} x_{\text {tcom }}$ represents tax interaction effects. After combining markets resulting in a higher carbon price, the already negative tax interaction effect on Hubei worsens by 0.39 percentage points (from -0.29 to -0.68 ). The negative tax iteration effect on Guangdong softens by 0.34 percentage points (from -0.51 to -0.17 ). This shows a lower carbon price ameliorates the pre-existing distortion. Also in Table 12, the sum of the trade contributions $\left(-S_{e} x_{e}+S_{m} x_{m}-S_{e r} x_{e r}\right.$ $+S_{m r} x_{m r}$ ) represents the terms of trade effect. Upon linkage, the positive terms of trade effect for Hubei strengthens by 0.37 percentage points (from 0 to 0.37 ), reflecting an improvement in terms of trade. The positive terms of trade effect for Guangdong shrinks by 0.77 percentage points (from 1.13 to 0.36), reflecting a deterioration in terms of trade. Overall, upon linkage, the combined effects of tax interaction and terms of trade contribute negatively to Hubei and Guangdong by 0.02 and 0.43 percentage points, respectively.

Comparing the contribution of capital and investment after linking, the combined contribution from the general equilibrium effects is moderate. This result should be read with caution, since in this simulation we adopt a long-run closure that controls real return to capital at its base year level while allowing investment to move in fixed proportion with capital employment. This makes real investment volatile ${ }^{1)}$. Indeed, our results support the general finding in the literature that equilibrium effects are significant in welfare distribution. It is the fact that tax interaction effects and terms of trade effects cancel each other that moderates their combined effects.

\subsection{Industry level impacts on GD and HB}

On the industry level, the impact of combining the two carbon markets follows the macro level impacts. The

1) When experimenting with a 'short-run' closure (in which on a national level, real rate of return is allowed to deviate from base year while real wage is fixed, employment will become the driving factor that determines GDP from the production side), we find contribution to GDP from investment significantly reduce. 
Table 12 Summarizes Eq. (18) for the two provinces under both scenarios

\begin{tabular}{|c|c|c|c|c|}
\hline \multirow{2}{*}{ Real Consumption } & \multicolumn{2}{|c|}{ NoLink } & \multicolumn{2}{|c|}{ Link } \\
\hline & Hubei & Guangdong & Hubei & Guangdong \\
\hline$\overline{S_{c} x_{c}}$ & -0.09 & -0.16 & 0.01 & -0.09 \\
\hline \multicolumn{5}{|l|}{$=$} \\
\hline$A$ & 0 & 0 & 0 & 0 \\
\hline$S_{n} x_{n}$ & 0.00 & 0.00 & 0.00 & 0.00 \\
\hline$S_{l} x_{l}$ & -0.21 & -0.46 & -0.52 & -0.16 \\
\hline$S_{k} x_{k}$ & -0.63 & -1.13 & -1.36 & -0.42 \\
\hline$S_{\text {tprod }} x_{\text {tprod }}$ & -0.02 & -0.03 & -0.05 & -0.01 \\
\hline$S_{\text {tcom }} x_{\text {tcom }}$ & -0.27 & -0.48 & -0.63 & -0.16 \\
\hline$-S_{i} x_{i}$ & 1.11 & 1.12 & 2.43 & 0.42 \\
\hline$-S_{g} x_{g}$ & 0.00 & 0.00 & 0.00 & 0.00 \\
\hline$-S_{q} x_{q}$ & -0.03 & -0.06 & -0.07 & -0.02 \\
\hline$-S_{e} x_{e}$ & 0.05 & 0.82 & 0.14 & 0.26 \\
\hline$S_{m} x_{m}$ & -0.08 & -0.44 & -0.17 & -0.19 \\
\hline$-S_{e r} x_{e r}$ & 1.22 & 1.46 & 2.84 & 0.58 \\
\hline$S_{m r} x_{m r}$ & -1.19 & -0.71 & -2.44 & -0.29 \\
\hline$-S_{n m r} x_{n m r}$ & -0.04 & -0.23 & -0.15 & -0.08 \\
\hline Sum RHS & -0.09 & -0.14 & 0.02 & -0.09 \\
\hline
\end{tabular}

Source: SinoTERMCo2 simulation results

industrial activity levels in Hubei generally decline against the industrial activity levels in Guangdong. Appendix 3 compares the impact of combining markets on different industries in the two provinces.

Despite the improved conditions for Guangdong's industries, we observe under both scenarios an overall general decline of industrial activity levels in both of the provinces (see Appendix 3). The industries that face the largest decline are those with the highest carbon emission intensities (see Figs. 1 and 2). In both of the provinces the number of such industries is low. The majority of the industries have a carbon emission to output ratio of less than one tonne per CNY. Only three industries (nonmetallic products, electricity and steam and non-metallic

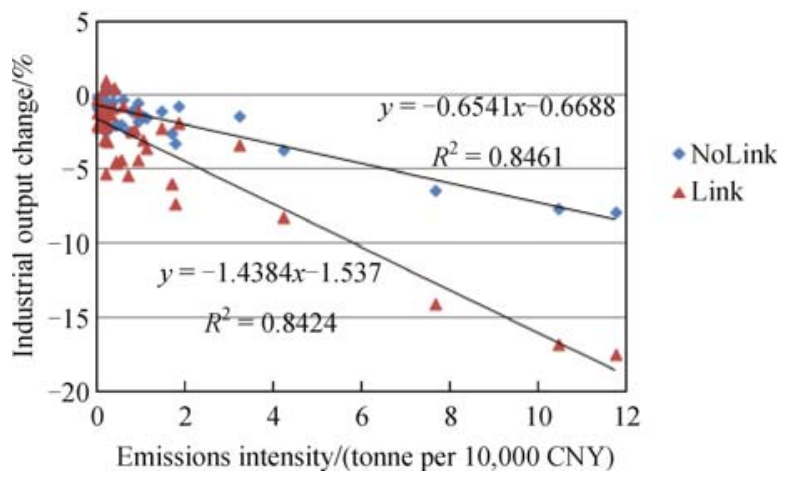

Fig. 1 Industrial output and emission intensity, Hubei.

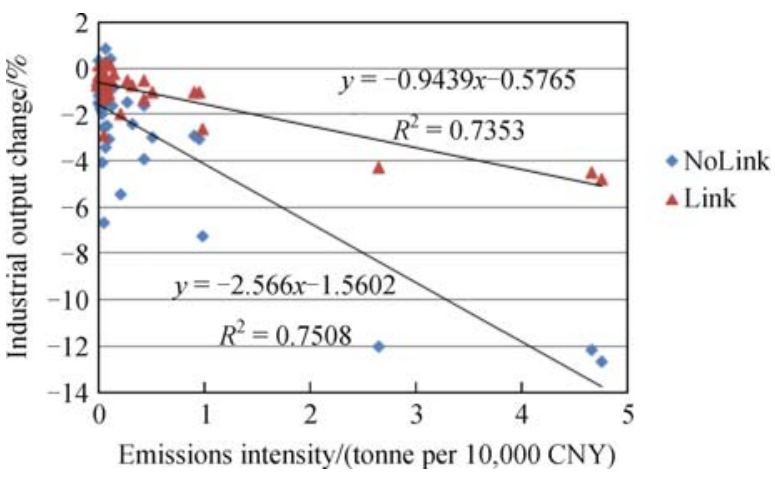

Fig. 2 Industrial output and emission intensity, Guangdong.

mining) in Guangdong, and five industries (transportation, chemical, metal smelting, non-metallic products, and electricity and steam) in Hubei have an emissions intensity of output more than 2 tonne per CNY. Hence the negative impact of the carbon market is severe on these few industries.

On top of the correlation between carbon intensity and output level, we also observe that industries with similar levels of carbon intensity may face significantly different impacts on their output levels. Five factors could explain such 'anomalies'.

First, the upstream and downstream connections play an important role. An industry may not produce a high volume of carbon dioxide emissions itself but it may be a key player along one or more emission-intensive indus- 
tries' production chains. In other words, the output of such industries complements those carbon intensive products. Therefore, when the activity level of the emissionintensive industries falls, it reduces the activity level of its complementary industries. For example, the metallic mining industry in both provinces has low emissions intensity, but since the majority of its outputs go to an emission intensive industry, namely metallic smelting, the activity level of metallic mining falls more than industries of similar emission intensities.

Second, producers face a lower labor cost relative to higher capital cost. This outcome derives from our assumptions on the labor and capital markets. We assume on the national level that the labor market tends to converge to full employment, and that real wage moves to accommodate the policy impacts. Conversely, the capital market tends to converge to a long-term real rate of return, and the level of capital moves to accommodate any policy impacts. The carbon price increases the expenditure price $(P g d p)$ relative to the production cost (Pprim). Since the real rate of return $\overline{(Q / P g d p)}$ to capital cannot react to mitigate this wedge, it leads to an increase in cost of capital to producers $(Q /$ Pprim). This leads to a) a decrease in the marginal productivity of capital $(M P K)$, which in turn reduces the capital-labor ratio, given that employment is relatively fixed by the national assumption. This reduction in capital-labor ratio reduces $b$ ) the marginal productivity of labor and therefore reduces producers' marginal labor cost.

$$
\begin{aligned}
& \uparrow(Q / \text { Pprim })=\overline{(Q / \text { Pgdp })} \times(\text { Pgdp/Pprim }) \uparrow \\
& \Rightarrow a)(Q / \text { Pprim }) \uparrow=M P K(K \downarrow / \bar{L}) \\
& \Rightarrow b)(W / \text { Pprim }) \downarrow=M P L(K \downarrow / \bar{L}) \\
& a), b) \Rightarrow(Q / W) \uparrow .
\end{aligned}
$$

Thus in Eq. (19), a) and $b$ ) together means capital cost become relatively higher than labor cost, this is good for the labor intensive industries and bad for the capital intensive industries. Hence, we observe on the top left corners of Fig. 1 and Fig. 2 an activity level increase for a small number of industries. Such industries, including education, agriculture, and public administration, are very labor intensive industries.

Third, the trade exposure of an industry also affects the impact to the industry. On the one hand, as Hubei and Guangdong's consumption and investment falls, they are going to demand less import, this will have a positive impact on the import-competing industries. On the other hand, as the outputs of the two provinces become more expensive, their exports become less competitive in national and world markets, and this will have a negative impact on export-oriented industries. Education and public administration are two industries that export little to other regions and they gain from limited trade exposure, whereas industries such as textile and electronic equipment are largely exported and they are hit by the weaker export demands.

Fourth, investment demand falls more than consumption demand. We observe that in both provinces the fall in investment is greater than the fall in consumption. This is partially a reflection that investment is typically more volatile than consumption, and partially a result of recycling carbon permit revenues back to consumers. As a consequence, industries that produce investment goods (e.g., construction) fall relatively more than industries that produce consumption goods (e.g., health, sports and recreation, and tourism).

Fifth, the characteristic of the margin-industries adds another dimension to consider. We notice that the transportation industry is relatively emission-intensive in both of the provinces, but their activity levels do not fall as much as industries with similar levels of emissions intensity (e.g., chemicals and coal and mining products). This is because the transportation industry mainly provides marginal services that facilitate trade among countries and regions. Although the level of trade activities decreases, they do not fall as much as the fall in emission-intensive activities. This prevents the demand for the transport industry from falling as much as its high emissions intensity indicates.

\subsection{Nationwide impacts}

The key parameter to assess the impact of integrating domestic carbon markets is the impact on carbon intensity of GDP, nationwide. We see from the previous analysis that Scenario Link leads to a smaller reduction in real GDP than Scenario NoLink. Given that the levels of emissions reduction are the same, the emissions intensity is also lower after combining markets. We can expand this analysis to the national level.

The fall in national real GDP would be smaller after constructing a nationwide integrating market. This follows the result that the real GDP of the Guangdong-Hubei bloc is larger in Scenario Link than in Scenario NoLink. The higher real GDP within the bloc generates stronger demand for outputs from other provinces, thus reduces the fall in real GDP after the combination.

However, the impact on national emissions is less predictable. On one hand, the relatively higher real GDP after the link is likely to lead to more economic activity and therefore more emissions. On the other hand, the relatively smaller contraction in the Guangdong-Hubei bloc after the link suggests that the bloc is likely to exert less carbon leakage to other provinces. Hence, on the national level, the total emissions level is likely to be determined by two countering effects: the positive impact on emissions from the rebound effect and the negative impact on emissions from carbon leakage. The simulation results show that on the national level emissions are lower after the link, suggesting that the negative carbon leakage effect 
Table 13 Key nation-wide indicators

\begin{tabular}{lccc}
\hline & Real GDP & Emissions & Emission intensity \\
\hline NoLink & -0.11 & -0.58 & -0.48 \\
Link & -0.06 & -0.79 & -0.73 \\
\hline
\end{tabular}

Source: SinoTERMCo2 simulation results

dominates the positive rebound effect (see Table 13) on overall emissions intensity.

The above results suggest that on the national level, combining these two carbon markets will unambiguously lead to a further fall in emissions intensity. This is because real GDP is higher whilst emissions are lower after the link. This is an interesting finding: it shows it is possible for each province to meet their original abatement targets but allow the nation to achieve lower emissions intensity upon linkage.

\section{Policy recommendation}

In this study we simulate the impacts of setting up pilot carbon markets in Hubei and Guangdong, separately and jointly. It is assumed that the stringency of each province's carbon market is proportional to its respective provincewide intensity-based abatement targets. According to the results, Guangdong will experience relatively more economic cost than Hubei when the two provinces separately commit to emissions trading. This shows that Guangdong is facing a tougher abatement target. On the industry level, the carbon market will have the strongest impact on the most carbon-intensive industries in both provinces no matter if the markets is separated or connected. The variances concerning industrial level impacts are also investigated. Such variances can be attributed to other mechanisms such as upstreamdownstream linkages. On the national level, the linking strategy results in higher total GDP and lower total emissions, leading to a roughly $0.2 \%$ reduction in the overall carbon intensity of GDP.

To summarize, the following insights can be drawn according to the simulation results. First, it is in the country's interest that regional ETS pilots are combined. This is concluded from the simulation results that when provincial abatement targets are met, linking carbon markets further reduces national emissions intensity. Second, there exist certain degrees of uneven distribution across the regions. The uneven distribution of welfare, measured by consumption, is not as significant as that of economic activities (notice, though, that this result is largely contingent on the assumption that all permit-selling revenues are handed back to consumers). Third, general equilibrium effects do matter as the size of tax interaction effects and terms of trade effects are non-negligible.

On the policy ground, to support the establishment of a nation-wide carbon market, China needs to abolish the current practice of top-down disaggregating national abatement targets.

The regional abatement targets will be irrelevant in a well-functioning, nation-wide carbon market. This is because what a nation-wide carbon market does is to let the market find the most efficient way of cutting carbon emissions. In order to do that, a nationwide cap is enough. The existence of regional abatement targets will not change the consequence that the least costly abatement option becomes the reality.

The existence of regional abatement targets makes it hard to build a nationwide carbon market. Take connecting Hubei and Guangdong's carbon markets as an example: if the two provinces faced the same emissions reduction targets, Hubei might still export abatement to Guangdong since Hubei's economy is relatively more emissionsintensive. Assigning Guangdong a more stringent abatement target only creates a larger wedge between the two province's autarky carbon prices. The equilibrium carbon price may still be around $36 \mathrm{CNY}$ per tonne in the linking carbon market. But without the regional abatement targets there will be much less transitional shock to both provinces, since their initial conditions wouldn't have been so far apart.

However, abolishing top-down abatement target disaggregation does not mean the government should give up the rationale behind disaggregating. As our simulation results have shown, linking carbon markets is likely to lead to uneven distribution of welfare and economic activities. In the absence of a national carbon market, assigning different abatement targets to different provinces could also act as a regional policy that protects less developed regions.

In this regard the government should be clear about its policy objectives. And it is often better to achieve one policy objective with one best policy option. There is no doubt that a nationwide carbon market is the most costefficient way to control carbon emissions. As a result the government should leave the full market mechanism in command. Still, the government should also address the market failures, such as increasing inequality, by supplemental policies. For example, it could use permit-selling revenues to cover part of the social security spending in less developed regions.

In the absence of regional abatement targets, it is also easier to evaluate the actual impact of welfare distribution by the carbon market. The results will be closer to reality since they will not be based on the pre-conditions that are already distorted by regional abatement targets. 
Acknowledgements This research is supported by the National Basic Research Program of China (No. 2012CB955700).

\section{References}

Babiker M, Reilly J, Viguier L (2004). Is international emissions trading always beneficial? Energy J (Camb Mass), 25(2): 33-56

Burniaux J M, Truong T P (2002). GTAP-E: An Energy-Environmental Version of the GTAP Model. GTAP Technical paper 16

Chen S Q, Chen B, Fath B D (2013). Ecological risk assessment on the system scale: a review of state-of-the-art models. Ecol Modell, 250: $25-33$

Chen Z M, Chen G Q (2011a). An overview of energy consumption of the globalized world economy. Energy Policy, 39(10): 5920-5928

Chen Z M, Chen G Q (2011b). Embodied carbon dioxide emission at supra-national scale: a coalition analysis for G7, BRIC, and the rest of the world. Energy Policy, 39(5): 2899-2909

Chen Z M, Chen G Q (2013a). Demand-driven energy requirement of world economy 2007: a multi-region input-output network simulation. Commun Nonlinear Sci Numer Simul, 18(7): 1757-1774

Chen Z M, Chen G Q (2013b). Virtual water accounting for the globalized world economy: national water footprint and international virtual water trade. Ecol Indic, 28: 142-149

Chen Z M, Chen G Q, Xia X H, Xu S Y (2012). Global network of embodied water flow by systems input-output simulation. Frontiers of Earth Science, 6(3): 331-344

Economist (2011). Comparing Chinese provinces with countries - All the parities in China [Online]. Available: http://www.economist.com/ content/chinese_equivalents [Accessed 22/09/2012 2012]

Flachsland C, Marschinski R, Edenhofer O (2009). To link or not to link: benefits and disadvantages of linking cap-and-trade systems. Climate Policy, 9(4): 358-372

He J W, Li S T (2010). Carbon reduction and regional economy. Manage Rev, 22(6): 9-16 (in Chinese)

Horridge M, Madden J, Wittwer G (2005). The impact of the 2002-2003 drought on Australia. J Policy Model, 27(3): 285-308

Horridge M, Wittwer G (2008). SinoTERM, a multi-regional CGE model of China. China Econ Rev, 19(4): 628-634

Hubacek K, Feng K S, Chen B (2012). Changing lifestyles towards a low carbon economy: an IPAT analysis for China. Energies, 5(1): 22-31

IOSCPRC (2011). State Council White Paper: China's Policies and Actions for Addressing Climate Change. Available: http://www.gov. cn/english/official/2011-11/22/content_2000272.htm [Accessed 20/ 01/2013]

Li J M, Huang Z H (2005). Cost of reducing carbon dioxide and strategy - Taiwan to participate in international emissions trading system. Economic Research, 41(2): 155-189 (in Chinese)

Li N, Shi M J, Yuan Y N (2010). Impacts of carbon tax policy on regional development in China: a dynamic simulation based on multi-regional CGE model. Geographical Science, 65(12): 15691580 (in Chinese)

Liang Q M, WeiY M (2012). Distributional impacts of taxing carbon in China: results from the CEEPA model. Appl Energy, 92(2): 545-551

Lin W B, Yang J, Chen B (2011). Temporal and spatial analysis of integrated energy and environment efficiency in China based on the Green GDP Index. Energies, 4(9): 1376-1390

Lipsey R G, Lancaster K (1956). The general theory of second best. Rev Econ Stud, 24(1): 11-32

Lokhov R, Welsch H (2008). Emission trading between Russia and the European Union: a CGE Analysis of potentials and impacts. Environ Econ Policy Stud, 9(1): 1-23

Mai Y, DixonP B, Rimmer M (2012). CHINAGEM: A Monash-Styled Dynamic CGE Model of China. CoPS/IMPACT Working Paper Number G-201

McDougall R, Golub A (2007). GTAP-E: A Revised EnergyEnvironmental Version of the GTAP Model. GTAP Resource \#2959

Nordhaus W D, Boyer J G (1999). Requiem for Kyoto: an economic analysis of the Kyoto protocol. Energy J (Camb Mass): 93-130

Ren Z Q (2008). Issues concerning global warming today. Frontiers of Earth Science, 2(1): 27-30

Stern D I, Pezzey J C V, Lambie N R (2011). Where in the World is it Cheapest to Cut Carbon Emissions? Ranking Countires by Total and Marginal Cost of Abatement. CCEP Working Paper 1111, Centre for Climate Economics \& Policy, Crawford School of Economics and Government, The Australian National University, Canberra.

Su M, Liang C, Chen B, Chen S, Yang Z (2012). Low-carbon development patterns: observations of typical Chinese cities. Energies, 5(2): 291-304

Webster M, Paltsev S, Reilly J (2010). The hedge value of international emissions trading under uncertainty. Energy Policy, 38(4): 17871796

Wei S K, Gnauck A, Lei A L (2009). Simulation analysis of domestic water demand and its future uncertainty in water scarce areas. Front Earth Sci China, 3(3): 349-360

Yang J, Chen B (2011). Using LMDI method to analyze the change of industrial $\mathrm{CO}_{2}$ emission from energy use in Chongqing. Frontiers of Earth Science, 5(1): 103-109

Yi H H, Hao J M, Tang X L (2007). Atmospheric environmental protection in China: current status, developmental trend and research emphasis. Energy Policy, 35(2): 907-915

Zhang L X, Feng Y Y, Chen B (2011). Alternative scenarios for the development of a low-carbon city: a case study of Beijing, China. Energies, 4(12): 2295-2310

\section{Appendixes}

Appendix 1: Data for $A_{i}$ and $B_{i}$

\begin{tabular}{lccc}
\hline Energy product $(i)$ & $A_{i}\left(\mathrm{kgCO}_{2} / \mathrm{TJ}\right)$ & \multicolumn{1}{c}{$B_{i}$} & Unit for $B_{i}$ \\
\hline Raw coal & 94,600 & 20,908 & $\mathrm{~kJ} / \mathrm{kg}$ \\
Washed coal & 94,600 & 26,344 & $\mathrm{~kJ} / \mathrm{kg}$ \\
Other washed coal & 94,600 & 8,363 & $\mathrm{~kJ} / \mathrm{kg}$ \\
Briquettes & 97,500 & 8,363 & $\mathrm{~kJ} / \mathrm{kg}$ \\
Coke & 107,000 & 28,435 & $\mathrm{~kJ} / \mathrm{kg}$ \\
Coke oven gas & 44,400 & 16,726 & $\mathrm{~kg} / \mathrm{m}^{3}$ \\
Other gas & 44,400 & 5,227 & $\mathrm{~kg} / \mathrm{m}^{3}$ \\
Crude oil & 73,300 & 41,816 & $\mathrm{~kJ} / \mathrm{kg}$ \\
\hline
\end{tabular}


(Continued)

\begin{tabular}{lccc}
\hline Energy product $(i)$ & $A_{i}\left(\mathrm{kgCO}_{2} / \mathrm{TJ}\right)$ & $B_{i}$ & $\mathrm{Unit}$ for $B_{i}$ \\
\hline Gasoline & 74,100 & 43,070 & $\mathrm{~kJ} / \mathrm{kg}$ \\
Kerosene & 71,500 & 43,070 & $\mathrm{~kJ} / \mathrm{kg}$ \\
Diesel oil & 74,100 & 42,652 & $\mathrm{~kJ} / \mathrm{kg}$ \\
Fuel oil & 74,100 & 41,816 & $\mathrm{~kJ} / \mathrm{kg}$ \\
LPG & 63,100 & 50,179 & $\mathrm{~kJ} / \mathrm{kg}$ \\
Refinery gas & 57,600 & 46,055 & $\mathrm{~kJ} / \mathrm{kg}$ \\
Natural Gas & 56,100 & 38,931 & $\mathrm{~kg} / \mathrm{m}^{3}$ \\
Other Petroleum & 73,300 & 41,816 & $\mathrm{~kJ} / \mathrm{kg}$ \\
products & & & \\
Other coking pro- & 107,000 & 33,453 & $\mathrm{~kJ} / \mathrm{kg}$ \\
ducts & & & \\
\hline
\end{tabular}

Source: 1: IPCC; 2: China Energy Statistical Yearbook.

Appendix 2: Emission intensity (t/CNY)

\begin{tabular}{|c|c|c|}
\hline & Guangdong & Hubei \\
\hline 1 AgriAll & 0.071 & 0.221 \\
\hline 2 Mining & 0 & 0.929 \\
\hline 3 CrudeOilGas & 0.952 & 1.868 \\
\hline 4 MetalMine & 0.218 & 1.773 \\
\hline 5 NonMetalMine & 4.751 & 1.704 \\
\hline 6 FoodTobcoPro & 0.278 & 0.577 \\
\hline 7 Textiles & 0.329 & 0.323 \\
\hline 8 ClthShoeLthr & 0.155 & 0.351 \\
\hline 9 SawmilFurnit & 0.07 & 0.241 \\
\hline 10 PaprPrntCult & 0.51 & 1.063 \\
\hline 11 PetrlRefCoke & 0.053 & 1.123 \\
\hline 12 Chemical & 0.427 & 4.227 \\
\hline 13 NMetalProdt & 2.652 & 11.741 \\
\hline 14 MetalSmelt & 0.981 & 7.665 \\
\hline 15 MetalPrds & 0.081 & 0.435 \\
\hline 16 GenerlSplEqp & 0.097 & 0.705 \\
\hline 17 ComuTransEqp & 0.044 & 0.251 \\
\hline 18 ElecEquip & 0.028 & 0.212 \\
\hline 19 ComuntComput & 0.018 & 0.124 \\
\hline 20 MetrsOffcEqp & 0.01 & 0.185 \\
\hline 21 ArtsCrafts & 0.071 & 0.783 \\
\hline 22 Scrap & 0.034 & 0.541 \\
\hline 23 ElecSteam & 4.656 & 10.469 \\
\hline 24 GasSupply & 0.054 & 0.118 \\
\hline 25 WaterSupply & 0.039 & 0.153 \\
\hline 26 Construction & 0.074 & 0.424 \\
\hline 27 TransWarehse & 0.911 & 3.211 \\
\hline 28 Post & 0.427 & 0.917 \\
\hline 29 ComptTrsSrvc & 0.003 & 0.043 \\
\hline
\end{tabular}

\begin{tabular}{lcc} 
& & $($ Continued $)$ \\
\hline 30 Trade & Guangdong & Hubei \\
31 HotelsDining & 0.006 & 0.024 \\
32 Finance & 0.14 & 1.466 \\
33 RealEstate & 0.013 & 0.142 \\
34 LeasCrclSrvc & 0.009 & 0.137 \\
35 Research & 0.074 & 0.87 \\
36 SynTechSrvc & 0.04 & 0.168 \\
37 WaterPubSrvc & 0.052 & 0.151 \\
38 ResidentSrvc & 0.031 & 0.036 \\
39 Education & 0.076 & 0.001 \\
40 HealthSocPub & 0.014 & 0.177 \\
41 CultSpotRecr & 0.049 & 0.137 \\
42 PublicAdmin & 0.025 & 0.219 \\
\hline
\end{tabular}

Source: SinoTERMCo2 database.

Appendix 3: Industrial activity level changes (\%)

\begin{tabular}{|c|c|c|c|c|}
\hline & \multicolumn{2}{|c|}{ Guangdong } & \multicolumn{2}{|c|}{ Hubei } \\
\hline & NoLink & Link & NoLink & Link \\
\hline 1 AgriAll & 0.86 & 0.28 & 0.41 & 0.92 \\
\hline 2 Mining & -0.77 & -0.74 & -1.77 & -4.37 \\
\hline 3 CrudeOilGas & -3.06 & -1.04 & -0.78 & -1.87 \\
\hline 4 MetalMine & -5.42 & -1.99 & -3.21 & -7.3 \\
\hline 5 NonMetalMine & -12.66 & -4.82 & -2.59 & -5.95 \\
\hline 6 FoodTobcoPro & -1.47 & -0.53 & -0.31 & -0.73 \\
\hline 7 Textiles & -2.37 & -0.75 & -0.59 & -1.33 \\
\hline 8 ClthShoeLthr & -0.82 & -0.24 & -0.37 & -0.81 \\
\hline 9 SawmilFurnit & -1.48 & -0.51 & -0.89 & -2.04 \\
\hline 10 PaprPrntCult & -2.98 & -1.04 & -1.37 & -3.03 \\
\hline 11 PetrlRefCoke & -2.53 & -0.86 & -1.52 & -3.59 \\
\hline 12 Chemcical & -3.93 & -1.34 & -3.66 & -8.24 \\
\hline 13 NMetalProdt & -12.01 & -4.28 & -7.9 & -17.46 \\
\hline 14 MetalSmelt & -7.26 & -2.59 & -6.39 & -14.04 \\
\hline 15 MetalPrds & -2.47 & -0.88 & -2.03 & -4.49 \\
\hline 16 GenerlSplEqp & -3.02 & -1.13 & -2.39 & -5.41 \\
\hline 17 ComuTransEqp & -1.99 & -0.73 & -1.34 & -3.07 \\
\hline 18 ElecGasMach & -1.77 & -0.67 & -2.42 & -5.31 \\
\hline 19 ComuntComput & -0.72 & -0.23 & -0.65 & -1.42 \\
\hline 20 MetrsOffcEqp & -0.86 & -0.28 & -0.93 & -2.05 \\
\hline 21 ArtsCrafts & -1.21 & -0.43 & -1.08 & -2.49 \\
\hline 22 Scrap & -1.66 & -0.62 & -2.02 & -4.41 \\
\hline 23 ElecSteam & -12.18 & -4.48 & -7.67 & -16.77 \\
\hline 24 GasSupply & -6.64 & -2.93 & -0.45 & -1.06 \\
\hline 25 WaterSupply & -4.04 & -1.35 & -1.42 & -3 \\
\hline
\end{tabular}




\begin{tabular}{|c|c|c|c|c|}
\hline & & & \multicolumn{2}{|c|}{ (Continued) } \\
\hline & \multicolumn{2}{|c|}{ Guangdong } & \multicolumn{2}{|c|}{ Hubei } \\
\hline & NoLink & Link & NoLink & Link \\
\hline 26 Construction & -3.41 & -1.26 & -2.04 & -4.62 \\
\hline 27 TransWarehse & -2.93 & -1.01 & -1.43 & -3.33 \\
\hline 28 Post & -1.64 & -0.54 & -0.49 & -1.13 \\
\hline 29 ComptTrsSrvc & -1.2 & -0.46 & -0.94 & -2.11 \\
\hline 30 Trade & -1.52 & -0.55 & -0.9 & -2.04 \\
\hline 31 HotelsDining & -1.6 & -0.57 & -1.03 & -2.27 \\
\hline 32 Finance & -1.47 & -0.56 & -0.95 & -2.08 \\
\hline 33 RealEstate & -0.71 & -0.34 & -0.49 & -1.01 \\
\hline 34 LeasCrclSrvc & -1.19 & -0.4 & -1.01 & -2.35 \\
\hline 35 Research & -1.16 & -0.39 & -0.59 & -1.37 \\
\hline 36 SynTechSrvc & -1.42 & -0.54 & -0.76 & -1.78 \\
\hline 37 WaterPubSrvc & -0.8 & -0.3 & -0.13 & -0.26 \\
\hline 38 ResidentSrvc & -1.31 & -0.52 & -0.53 & -1.18 \\
\hline 39 Education & 0.37 & 0.11 & 0.17 & 0.4 \\
\hline 40 HealthSocPub & -0.66 & -0.24 & -0.36 & -0.83 \\
\hline 41 CultSpotRecr & -0.69 & -0.21 & -0.36 & -0.82 \\
\hline 42 PublicAdmin & 0.43 & 0.15 & 0.26 & 0.55 \\
\hline
\end{tabular}

Source: SinoTERMCo2 simulation results. 